\title{
Research on the Framework of the Issue of the Guangdong-Hong Kong-Macao Greater Bay Area by American Think Tank Network Media
}

\author{
Dan $\mathrm{Lu}^{1, *}$ Shanyan Chen ${ }^{1}$ Xuefei Tan ${ }^{2}$
}

\author{
${ }^{I}$ Beijing Normal University at Zhuhai, Zhuhai, Guangdong 519087, China \\ ${ }^{2}$ National Research Center of Cultural Industries, Central China Normal University, Wuhan, Hubei 430079, \\ China \\ *Corresponding author. Email: lynn98019@126.com
}

\begin{abstract}
This article takes the research trends of the American think tank network media on the Guangdong-Hong KongMacao Greater Bay Area as the object of analysis, and uses the framework theory to analyze the characteristics of the theme, emotions, and attitudes of the US think tanks on the issues in Guangdong, in order to summarize the American think tanks' public opinion orientation and political attitude on Guangdong, enhance the influence of New Year's cultural dissemination and open up a foreign vision for Guangdong think tank.
\end{abstract}

Keywords: Think tank, Guangdong-Hong Kong-Macao Greater Bay Area, Internet media.

\section{INTRODUCTION}

As a special institution for producing and disseminating ideas, think tanks are regarded as one of the main bodies of the global knowledge production system. The United States is not only the birthplace of modern think tanks, but also promotes the development of American think tanks because of its status as a world political and economic power. In addition to providing reference for domestic decision-making, American think tanks will also provide guidance by investigating the global strategic game between countries. Due to the rapid expansion of China's influence in the world in recent years, American think tanks have also strengthened their research strength in various regions and fields of China, so as to further follow up the situation of China and serve the national interests of the United States. [1]

Since Premier Li Keqiang first mentioned "Guangdong-Hong Kong-Macao Greater Bay Area" in the government work report in 2017, foreign media have been paying close attention to it, and

*Fund: This article is supported by the research results of 2018 Guangdong Ordinary University Characteristic Innovation Project - "Research on the Construction Path of Guangdong's New-type Think Tank Public Opinion Communication Power in the New Media Era" (2018WTSCX195).
Guangdong's economic influence has gradually increased. As a national development strategy, the Guangdong-Hong Kong-Macao Greater Bay Area has brought the cooperation among Hong Kong, Macao and the Pearl River Delta to a new level. Under the guidance and support of the national strategy, the Great Bay Area will further unite and activate the economy of the three regions. Combined with the other advantages of each region and the existing development achievements, the Great Bay Area will not only become the largest Bay Area in the world, but also may become an international science and technology innovation center, a world-class financial town and platform. This will also contribute to the further transformation and upgrading of Hong Kong's economy and industrial structure. American think tanks also pay attention to this major regional development plan in China. Based on this, this study intends to analyze the latest research trends of American think tanks on Guangdong, in order to better understand the degree of attention and presentation of American think tanks' online media to Guangdong, and to expand the vision outside the region to explore the promotion of the cultural communication power of Guangdong's new think tanks in the era of new media. 


\section{LITERATURE REVIEW}

\subsection{Research on American Think Tanks}

Modern think tanks originated in the United States in the early 20th century. The think tanks studied in this paper refer to American think tanks. American scholars initially regarded think tanks as a "non-profit public policy research industry", and then gradually defined them as "public policy research and advocacy organizations", which played an increasingly important role in the field of public policy in the United States. The internal logic of think tanks' operation is "to raise social funds, produce research products, provide policy suggestions, and promote policy optimization, so as to achieve their own public value". This logic reflects some basic characteristics of think tanks, such as independence, non-profit and specialization, which have been widely recognized by the public. With the development of American think tanks, different think tanks can be divided into academic, contract and advocacy types according to their own characteristics. Academic think tanks are mainly composed of professional academic researchers who study social and public policies with an objective and neutral attitude and academic spirit; The contract think tank has a contractual relationship with the government to provide solutions for the decision-making of government departments; Advocacy think tanks have a clear ideology, clear political position, actively advocate policy and actively promote policy influence. [2]

\subsection{Research on Frame Theory}

The theoretical sources of frame analysis are mainly psychological cognition and sociology. The concept of "frame" was first put forward in Bateson's "theory of drama and fantasy" published in 1955. Later, Goffman introduced the concept of "frame" into the humanities and social sciences in the book "frame analysis" in 1974. After being followed by Entenmann and others, frame theory has become an important concept in journalism and communication. [3] Frame theory has attracted many scholars in the field of journalism and communication. In addition to summarizing the categories of frame theory such as "interpretive package" and "frame list", Zang Guoren, a Taiwan scholar, has made another important contribution of dividing the frame into three levels: high level, medium level and low level. At the high level, it defines the fact theme; at the middle level, it refers to the structure composed of attribution, influence and description; at the lower level, it refers to the more micro selection mechanism, including the choice of words, sentences and so on.

\subsection{Research on Greater Bay Area}

As the fourth largest Bay Area in the world after New York Bay area, San Francisco Bay Area and Tokyo Bay Area, the economic influence of Guangdong-Hong Kong-Macao Greater Bay Area has ranked first among the four Bay Areas. Therefore, the reports and researches on Guangdong-Hong Kong-Macao Greater Bay Area are increasing. Most of the existing studies focus on the economic construction and regional cooperation of Guangdong-Hong Kong-Macao Greater Bay Area, while few studies are conducted from the perspective of cultural communication. Only scholars conduct empirical research based on the reports of 182 foreign media on Guangdong-Hong Kong-Macao Greater Bay Area, and explore the path selection of external communication of Guangdong-Hong Kong-Macao Greater Bay Area. [4] At present, there is no paper selecting the Internet media of American think tank as the research object, which is also the significance of this paper.

\section{RESEARCH DESIGN}

\subsection{Research Questions}

This study will be based on the frame analysis, which is divided into three levels: high, medium and low levels. And then, the content of Guangdong in American think tanks can be analyzed. The research questions are as follows:

- Q1: what macro-level themes and refining frameworks do American think tanks focus on in their research on Guangdong?

- Q2: what is the tendency of middle-level issues in the research of Guangdong by American think tanks?

- Q3: what are the meso-level sources of American think tanks' research on Guangdong?

- Q4: what are the micro linguistic features of American think tanks' research on Guangdong? 


\subsection{Data Selection}

\subsubsection{The Choice of Think Tanks}

In the selection of think tanks, it mainly refers to the list of famous American think tanks in the "think tanks" entry of "Chinese Wikipedia". Among the nine think tanks listed, the official websites of the National Academy of Sciences and the Center for Advanced Defense Research failed to retrieve any content related to Guangdong, and they were excluded. At the same time, according to the Global Go To Think Tank Index jointly released by the Think Tanks and Civil Society Program and the University of Pennsylvania in 2015, the remaining seven think tanks all rank among the top 20 think tanks in the United States. It shows that these seven think tanks have a certain degree of credibility and authority in the United States. Therefore, this research selects seven think tanks, such as "Carnegie Foundation for International Peace", "American Heritage Foundation", "Peterson Institute for International Economics", "Strategic and International Research Center", "Brookings Institution", "Rand Corporation" and the Hoover Institution, as the research objects.

\subsubsection{Time Division}

In recent years, Guangdong has become the focus of national regional development due to the construction of the Guangdong-Hong Kong-Macao Greater Bay Area. In 2014, the Shenzhen Municipal Government Work Report took the lead in proposing the idea of "Building the Bay Area Economy". Subsequently, the introduction of local policies gradually promoted the implementation of the national strategy. In March 2016, the "outline of the 13th five-year plan for national economic and social development of the People's Republic of China" was officially released, which clearly put forward "supporting Hong Kong and Macao to play an important role in the Pan Pearl River Delta regional cooperation, and promoting the construction of major cooperation platforms in Guangdong-Hong Kong-Macao Greater Bay Area and inter provincial areas". The State Council also issued the "guiding opinions on deepening the regional cooperation in the Pan Pearl River Delta", which clearly requires Guangzhou and Shenzhen to join hands with Hong Kong and Macao to build Guangdong-Hong Kong-Macao Greater Bay Area and build a world-class urban agglomeration. 2015 can be regarded as an important turning point for Guangdong to build Guangdong-Hong Kong-
Macao Greater Bay Area, and it is also the first focus before Guangdong develops into a national city. Therefore, this study sets the time period from January 1, 2015 to June 30, 2020.

\subsubsection{Keyword Retrieval}

In addition to the English word "Guangdong", Guangdong can also be represented by the Pearl River Delta, the Pearl River basin / Pearl River Mouth Basin, and the Greater Bay area. Both the Pearl River Delta and the Pearl River Mouth Basin contain the keyword "Pearl River", which can be used directly in the retrieval process. This study uses "Guangdong", "Pearl River" and "Greater Bay Area" as keywords in the official websites of the above think tanks, and searches all the texts that mentioned the above keywords in recent five years by means of keyword full-text retrieval. A total of 52 articles were obtained after the texts with low correlation were manually screened out. Among them, three papers are from "Carnegie Foundation for International Peace", three papers are from "American Heritage Foundation", nine papers are from "Peterson Institute for International Economics", seven papers are from "Strategic and International Research Center", nineteen papers are from "Brookings Institution", nine papers are from "Rand Corporation" and two papers are from the Hoover Institution. It is worth noting that the samples selected in this study are only limited to articles, reports, news reports, documents and meeting minutes published by think tanks through the official website, and other texts that need permission are not included in the sample collection scope of this study.

Combined with the classification of articles on the official website and manual reading, the samples cover nine fields: politics, economy, medical treatment, law, society, environment, education, military and history. Based on this, the reliability of the samples was analyzed by SPSS26.0 software, and the Cronbach's Alpha coefficient was 0.610. According to the data after deleting "Cronbach's Alpha coefficient behind items", if two samples in the historical field are excluded, the value of Cronbach's Alpha coefficient can reach 0.693. As the only two articles of Hoover Institution are in the field of history, the effective sample of this study is 50 . 


\subsubsection{Framework Analysis}

Combined with the related research results of predecessors [5], the specific operation steps of the framework analysis in this study are as follows: coding the specific content of 50 effective samples, determining the keywords of the samples, obtaining the theme, summarizing the theme, and obtaining the broad frame. Then, Q1 can be answered. After coding the samples, 15 keywords such as "Greater
Bay Area", "free trade zone" and "manufacturing industry" were obtained, and 12 themes such as "globalization" were created accordingly. Based on this, referring to the five specific indicators of "general framework" proposed by Semetko \& Valkenburg (2000), six refining frameworks, including "responsibility", "economic impact", "humanity", "conflict", "Chinese politics" and "others", are extracted combining with the actual situation of this study, as shown in "Table 1".

Table 1. Framework classification of issues of Guangdong-Hong Kong-Macao Greater Bay Area by American think tanks

\begin{tabular}{|c|c|c|c|c|c|c|c|}
\hline $\begin{array}{l}\text { Frame } \\
\text { category }\end{array}$ & responsibility & $\begin{array}{l}\text { Economic } \\
\text { Impact }\end{array}$ & humanity & Conflict & $\begin{array}{l}\text { Chinese } \\
\text { politics }\end{array}$ & others & Total \\
\hline $\begin{array}{l}\text { frequency of } \\
\text { occurrence }\end{array}$ & $14(28 \%)$ & $10(20 \%)$ & $9(18 \%)$ & $2(4 \%)$ & $10(20 \%)$ & $5(10 \%)$ & $50(100 \%)$ \\
\hline
\end{tabular}

\subsubsection{Responsibility Framework [6]}

The classification index of responsibility framework is whether the contents ascribe the cause or solution of the event to the responsibility of the government, individual or group. In this study, the conference held by Guangdong, Guangdong's participation in the process of globalization, and relevant environmental protection practices of Guangdong Province are all classified under the responsibility framework, which mainly focuses on the responsibility of the responsible party. The proportion of this framework is $28 \%$, which is the highest among the six frameworks in this study.

\subsubsection{Economic Impact Framework}

The classification index of economic impact framework is whether the content refers to the economic impact of an event on individuals, groups, institutions, regions or countries. Under this standard, the contents of "going out" of Guangdong enterprises and Guangdong's financial situation in the samples all belong to the economic impact framework. Among them, more than half of contents of Guangdong enterprises are international or Hong Kong, Macao and Taiwan. The framework accounts for $20 \%$, second only to the responsibility framework.

\subsubsection{Humanity Frame}

The classification index of humanity frame is whether the contents reflect the humanistic care in the event. The humanity framework of this study mainly points to epidemic-related, people's livelihood, environmental protection and other topics, and the contents show the concern for individuals. The framework accounts for $18 \%$.

\subsubsection{Conflict Framework}

The classification index of conflict framework is whether the content emphasizes the conflict among individuals, groups or institutions in the event. In the sample, the content reflecting Guangdong-related involved the least number of conflicts, accounting for only 4\%. These two articles, which belong to the conflict framework, both contain military exercises and have nothing to do with the real military conflict.

\subsubsection{China's Political Framework}

Different from the previous frameworks, China's political framework is constructed based on the particularity of this study. The content is directly or indirectly related to China's politics, and it is difficult to simply put it into the five "general frameworks" of responsibility, economic impact, humanity, conflict or morality. Therefore, it is called China's political framework. Under the framework of Chinese politics, the content includes the leaders of Guangdong Province and the state, or refers to the politics of Hong Kong, Macao and Taiwan or their relationship with Guangdong. The proportion of this framework is also $20 \%$, which is consistent with the number of samples under the economic impact framework.

\subsubsection{Other Framework}

After learning from four of the five "general frameworks" and putting forward China's political framework, the rest of the contents cannot be 
divided into any framework, and the correlation between the contents is low, so the remaining samples are uniformly classified into other frameworks.

\subsubsection{Analysis of Emotional Attitude Tendency}

This study mainly divides the emotional attitude tendencies into three types: being promotional, neutral and conservative. As a result, Q2 can be answered. Referring to the previous coding method of scholars, the tendency of topics in the sample is coded as (1) Promotional $=1(2)$ Neutral $=0$ ( 3) Conservative $=-1$

\subsubsection{Corpus Analysis}

This study uses the AntConc to process the data in the samples with reference to the British National Corpus. By searching the node words such as "say", "saying" and "said", the source information can be located to answer Q3. In addition, with the help of the corpus tool, the keyword list is generated after the statistics of word frequency, and the top 20 high-frequency notional words are retrieved in the corpus. The specific meaning of the top 20 high-frequency notional words in the context is investigated to analyze the linguistic characteristics of the samples, so as to answer Q4.

\section{RESEARCH RESULTS}

\subsection{Theme and Frame Features}

During the framework analysis, 12 themes such as "globalization", "Hong Kong, Macao and Taiwan", "leadership" can be summarized from the keywords by specific subdivision of the six frameworks such as "responsibility", "economic influence", "human feelings", "conflict", "Chinese politics" and "others", as shown in "Figure 1" below.

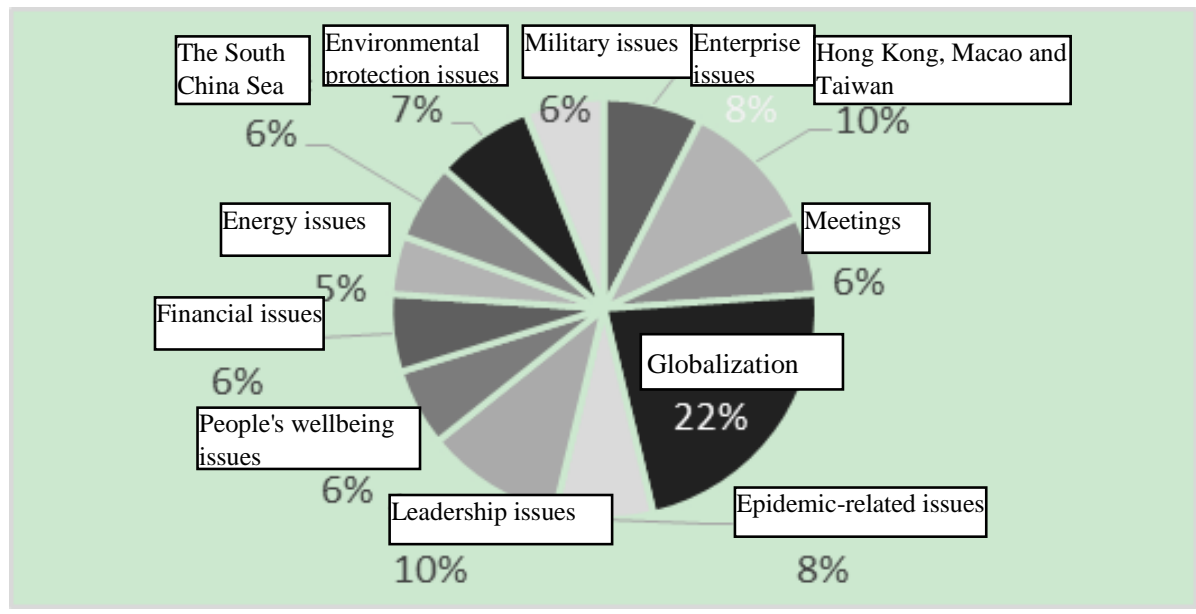

Figure 1 The topic classification of the issues of Guangdong-Hong Kong-Macao Greater Bay Area by American think tank.

\subsubsection{Globalization Is a Prominent Topic in Guangdong}

The American think tank not only discusses the relationship between Guangdong economy and the world, such as the development of Guangdong enterprises abroad, but also studies the role of Guangdong in the process of communication between China and other countries. The significance of globalization theme reflects the distinctive characteristics of the times. To some extent, it also emphasizes the more important role of Guangdong in promoting China's international cooperation.

\subsubsection{Reflecting the Development Vision of Guangdong}

Whether Guangdong is regarded as the narrative subject or Guangdong as an example, the description of Guangdong in content mostly reflects the concern of the responsible party. In the face of Guangdong's development and the rise of China, most of the issues of American think tanks are based on dialogue and understanding, so as to make efforts to promote mutual benefit and win-win results. 


\subsubsection{Attaching Importance to Guangdong Economy}

The economic development of Guangdong is improving. American think tanks pay attention to the cooperation and internal finance of all parties at the economic level, including the discussion on the construction of free trade zone, the status of manufacturing industry, and the promotion of Guangdong-Hong Kong-Macao Greater Bay Area on economy. However, the construction of Guangdong economic image by American think tanks is mostly on the macro-level, which makes it difficult for Guangdong to show diversified characteristics.

\subsubsection{Focusing on Chinese Politics}

Guangdong is often seen as an entry point for insight into Chinese politics. In the high-frequency word list, the sixth word is "party", which appears 20 times and is used to describe the leaders of Guangdong or the state. At the same time, Guangdong is not only geographically close to Hong Kong and Macao, but also has close economic ties with Hong Kong, Macao and Taiwan. Some articles about Hong Kong, Macao and Taiwan often refer to Guangdong.

\subsection{Attitude Tendency Features}

The study of attitude tendency in this study is based on the framework analysis, while the discussion of Guangdong issues by American think tanks basically follows the principles of being neutral and conservative. The reason why Guangdong tends to be neutral on the whole is that most of them appear as examples in this paper. But being promotional and conservative is in the minority, and the proportion is close, as shown in "Figure 2". In addition, except the word "development" (14 times) has a relatively positive meaning, the other high-frequency words have no clear distinction between praise and criticism.

When Guangdong appears as a positive example, it has a positive attitude towards some environmental protection and epidemic response measures in Guangdong. However, when it comes to some sensitive issues, such as the failure to reach an agreement on Sino-US trade issues and the political issues on Hong Kong and Taiwan, Guangdong is conservative in its role. However, it is worth noting that the content with relatively negative attitude shows the tendency that American think tanks are hard to get rid of stereotype on Guangdong issues, especially in the description of the relationship between Guangdong and Hong Kong, Macao and Taiwan.

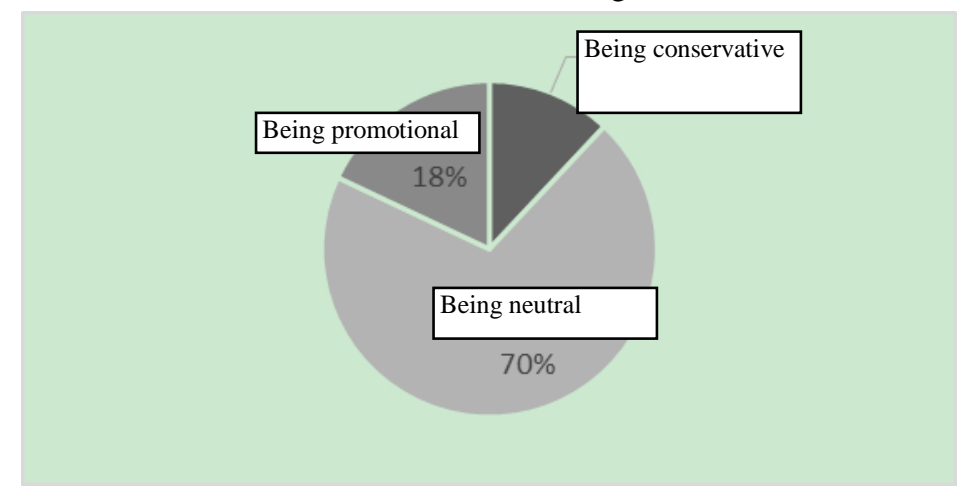

Figure 2 Classification of attitude tendencies of American think tanks towards issues on Guangdong-Hong Kong-Macao Greater Bay Area.

\subsection{Source Characteristics}

Referring to the past research path of scholars [7], the source analysis of this study is based on corpus information, that is, to explore the source distribution by searching the words such as "say", "saying", "said". However, when searching the samples, it is found that "say" and "said" only appear twice, while "said" never appears. Combined with the context, the provenance of "say" and "said" are independent of the source. As a whole, most articles take a small space mentioning Guangdong, and it is difficult to reflect the information sources. Therefore, this study cannot analyze the source-related samples in detail at the meso-level. 


\subsection{Linguistic Features}

This study uses the statistical information of the corpus to interpret the linguistic features at the micro level. "China" (112 times) appears more than "Guangdong" (93 times), which is the most frequent word in the samples. This means that when discussing the Guangdong issue, it is closely related to the overall context of China. The repeated appearance of "economic" (27 times) and "party" (20 times) shows that economy and politics are the most concerned fields of American think tanks, which is also consistent with the findings in this study, as shown in "Figure 3". American think tanks are more concerned about the economic and political image of Guangdong, but they lack the researches on the issues of Guangdong from a social, historical and cultural perspective.

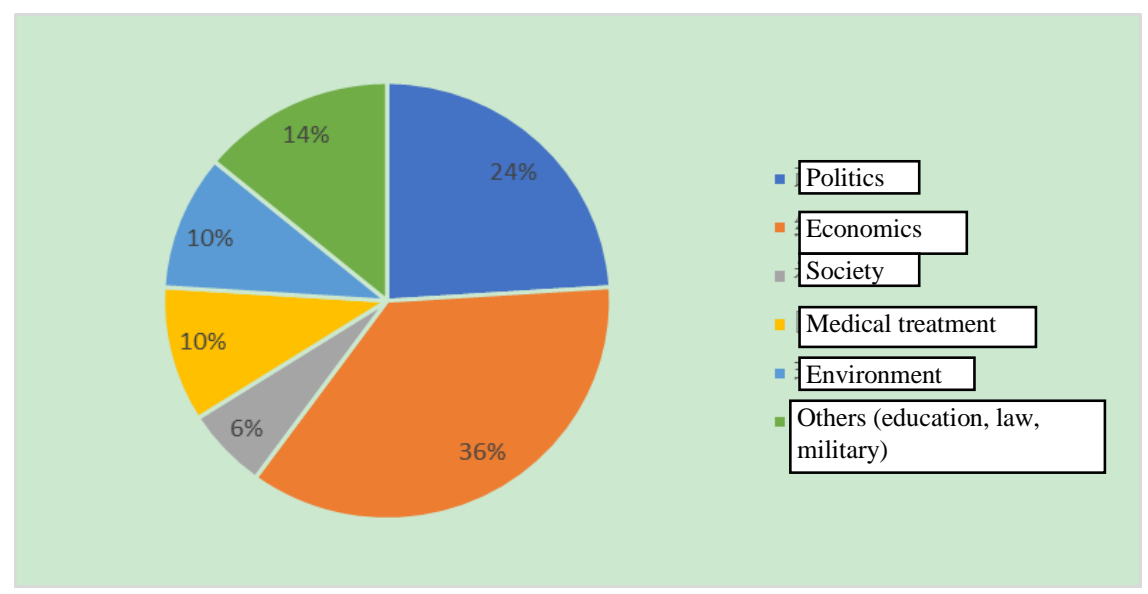

Figure 3 Classification of research fields of Guangdong-Hong Kong-Macao Greater Bay Area by American think tanks.

Modal verbs such as "can" (19 times) and "will" (18 times) rank seventh and eighth in the keyword list respectively, which are high-frequency words. The word "can" is in a firm sense, and "will" have the expression of sustainable development in the future.

\section{CONCLUSION}

Based on the above analysis, people can draw the following conclusions. First, American think tanks pay attention to the dynamic of GuangdongHong Kong-Macao Greater Bay Area and the role of Guangdong economy in the global development, but the content is mostly on the macro level, and the presentation of Guangdong image is not diversified and objective. Second, from a politically dominant perspective, American think tanks are positive about Guangdong's measures on environmental protection and epidemic prevention, but negative about issues closely related to the political issues of Hong Kong and Macao. Third, American think tanks have some deficiencies in the social and historical and cultural perspectives on Guangdong issue, and is wary of China's development and economic rise. Based on the above analysis, think tanks in Guangdong Province of China should fully understand the importance of their own information communication and image construction in international communication, expand the influence of think tanks in Guangdong Province through media means, improve the crosscultural communication role of Chinese think tanks, and better serve the modernization of national governance system and governance capacity, and further promote "Chinese voice" in Guangdong economic and political development with the use of international network media broadcast.

\section{AUTHORS' CONTRIBUTIONS}

Dan Lu: designed research. Shanyan Chen: analyzed data, and wrote the paper. Xuefei Tan: checked data. All authors contributed to the writing and revisions.

\section{REFERENCES}

[1] Zhao Hengyu. A Research of American Think Tank's Perspectives on China:Synthetic Analysis of China Issue Reports of Brookings Institute [J]. Journal of Information, 2020, 39(02). (in Chinese)

[2] Zhang Ning, Wang Jingjun. Convergence and Deviation: A Comparative Analysis of the 
Attribute Networks of American Think Tanks and Government Departments Concerning China. Hubei Social Sciences, 2019 (12). (in Chinese)

[3] Ding Hegen. The Comparison of Discourse Analysis and Frame Analysis in News Communication Research [J]. Contemporary Communication, 2019(06). (in Chinese)

[4] Du Mingxi, Hou Yingzhong. Analysis on the Choice of External Communication Paths in the Guangdong-Hong Kong-Macao Greater Bay Area under the Mirror of Foreign Media - An Empirical Study Based on 182 Foreign Media Reports. External Communication, 2020 (4). (in Chinese)

[5] Wang J. "Stir-Frying" Internet Finance: Financialization and the Institutional Role of Financial News in China [J]. International Journal of Communication, 2017, 11.

[6] HA Semetko,PM Valkenburg. Framing European politics: a content analysis of press and television news[J]. Journal of Communication, 2000, 50(2).

[7] Qian Jingjing, Zhang Hanzhi. From "the Imagined Other" to the Non-Western's Self Media Representation: A Study with Combined Approach of News Frame Analysis and Corpus-based Study on International Business Reporting [J]. Journal of China University of Geosciences (Social Sciences Edition), 2018, 18(06). (in Chinese) 